\title{
Prevalence of Musculoskeletal Pain and Analgesic Treatment Among Community-Dwelling Older Adults: Changes from 1999 to 2019
}

\author{
Tuuli Elina Lehti ${ }^{1,2,3}$ (1) M.-O. Rinkinen ${ }^{3} \cdot$ U. Aalto ${ }^{2,3} \cdot$ H. M. Roitto ${ }^{2,3} \cdot$ M. Knuutila ${ }^{2,3} \cdot$ H. Öhman ${ }^{4} \cdot$ H. Kautiainen ${ }^{3}$. \\ H. Karppinen ${ }^{3} \cdot$ R. Tilvis ${ }^{5} \cdot$ T. Strandberg $^{5,6} \cdot$ K. H. Pitkälä ${ }^{1,3}$
}

Accepted: 25 July 2021 / Published online: 13 August 2021

(c) The Author(s) 2021

\begin{abstract}
Background Pain is undertreated in older populations. At the same time, increased use of opioids is of concern in the Western world.

Aims We sought to analyze temporal trends in musculoskeletal pain and prescribed analgesic treatment among communitydwelling people aged $75-95$ years using cross-sectional cohort data spanning 20 years.

Methods The Helsinki Aging Study recruited random samples of people aged 75, 80, 85, 90, and 95 years in 1999, 2009, and 2019. In total, 5707 community-dwelling persons participated in the study. The participants reported their medical diagnoses, regular prescription medications, and the presence of back pain or joint pain within the last 2 weeks (never, sometimes, or daily). We compared analgesic use among participants reporting and not reporting musculoskeletal pain in 1999, 2009, and 2019.

Results Of the participants, 57-61\% reported intermittent or daily musculoskeletal pain. The percentage receiving a prescribed daily analgesic increased from $9 \%$ in 1999 to $16 \%$ in 2019. The use of non-steroidal anti-inflammatory drugs (NSAIDs) decreased from 1999 to 2019, while the use of paracetamol increased from 2 to $11 \%$. Opioids were taken by $2 \%$ in 1999 and 3\% in 2019. Of those reporting daily musculoskeletal pain, 20\%, 35\%, and 32\% received regular pain medication in 1999, 2009, and 2019, respectively.

Conclusions Pain remains undertreated in the community-dwelling older population, although the use of regular prescribed analgesics increased between 1999 and 2019. The use of NSAIDs has decreased, while the use of paracetamol has increased. Daily opioid use has remained modest.
\end{abstract}

Tuuli Elina Lehti

tuuli.lehti@helsinki.fi

1 Primary Health Care Unit, Helsinki University Hospital, Ilkantie 10 B 22, 00400 Helsinki, Finland

2 Social Services and Health Care Division, City of Helsinki, Helsinki, Finland

3 Department of General Practice and Primary Health Care, University of Helsinki, Helsinki, Finland

4 Geriatric Medicine, University of Helsinki and Helsinki University Hospital, Helsinki, Finland

5 Geriatric Unit, Department of Internal Medicine, University of Helsinki, Helsinki, Finland

6 Center for Life Course Health Research, University of Oulu, Oulu, Finland

\section{Introduction}

Pain is a common source of suffering; up to $40 \%$ of primary health care visits are due to pain in the general population [1]. In epidemiologic studies, the prevalence of bothersome pain among older adults (age $>65$ years) is over $50 \%[2,3]$, with the back and major joints being the most common pain sites [1, 4-6]. Pain is undertreated in the older population [3, 7-9] and leads to reduced social contacts and ambulation, sleep disturbances, symptoms of depression and anxiety, and increased health care use and costs [10]. However, the experience of pain has not decreased even though the use of prescription analgesics has increased in recent decades [9].

The popularity of paracetamol (acetaminophen) has increased while the regular use of non-steroidal anti-inflammatory drugs (NSAIDs) has decreased [9, 11, 12]. This is in accordance with the known risks of gastrointestinal bleeding, hypertension, cardiovascular events, and renal failure associated with NSAIDs, especially among people with comorbidities and polypharmacy. The use of opioids has 


\section{Key Points}

Pain is common and undertreated in the older population and leads to reduced quality of life.

Regular analgesic use increased from 1999 to 2019 among community-dwelling people aged 75-95 years; however, daily musculoskeletal pain did not decrease.

Opioids were not widely used. Paracetamol use increased.

increased in institutionalized settings [13] and in the general population [14-17], raising concerns about serious risks associated with their use in the aging population.

Recent developments in analgesic prescribing in geriatric populations have not been thoroughly examined. Opioid use in older populations has been addressed in only a few studies $[12,18,19]$, and overall pain management in the oldest-old outside institutionalized settings has received little attention. This study analyzed time trends in analgesics use among 75- to 95-year-old community-dwelling persons using cohort data from 1999 to 2019 . We compared regular analgesic use among people reporting daily versus intermittent musculoskeletal pain that hinders daily activity and among people not reporting musculoskeletal pain. Further, we examined time trends in the use of various classes of analgesics.

\section{Methods}

\subsection{Study Design and Participants}

The Helsinki Aging Study is a survey-based, cross-sectional cohort study that aims to monitor changes in common medical conditions, medications, symptoms, self-reported measures of wellbeing, health, and daily functioning in the community-dwelling older population in the urban Helsinki area in Finland (population 600,000). Random cohorts retrieved from the Finnish Population Information system of people aged $75,80,85,90$, and 95 years were invited to participate in the study in 1999, 2009, and 2019. One reminder was sent to non-responders. The 1999 study recruited 3921 participants. A total of 2633 participants were recruited in 2009 and 2789 participants were recruited in 2019. One reminder was sent to those who had not responded to the survey. Of the recruited participants, $80 \%$ responded to the survey in $1999,73 \%$ in 2009 , and $74 \%$ in 2019 . The response rates are estimates based on how many questionnaire recipients had passed away, moved, or been institutionalized since the most recent Helsinki census.
Respondents who reported living in long-term institutional care as well as respondents who had not answered the questions of interest (see Sect. 2.2.2) were excluded from analysis.

The study design was approved by the Helsinki University Hospital Ethics Committee.

\subsection{Measures}

\subsubsection{Participant Characteristics}

Demographic information on education (number of years) and marital status was self-reported in the questionnaire ("Are you married or cohabiting/unmarried/divorced or separated/widowed?"). Age and sex were extracted from the participant's Finnish personal identity code. Participants were asked to report their diagnosed diseases (yes/ no answers, 20 common diseases), from which we calculated the Charlson comorbidity index [20]. The participants were asked to rate their health on a four-step scale (healthy, moderately healthy, moderately unhealthy, very unhealthy). The first two options (healthy or moderately healthy) were categorized as good self-rated health. Functional capacity was assessed with a question: "Is your general condition such that you can move outside unaided?" (Yes/No, I need a walking stick or a rollator/No, I need another person's help/ No, I cannot move outside).

\subsubsection{Musculoskeletal Pain}

The participants were asked whether they had experienced back pain that hinders activity or joint pain that hinders activity within the last 2 weeks on a three-step scale (never, sometimes, or daily).

Together with pain, we inquired about other common symptoms (8-10 symptoms in total, depending on the study year), and the participants rated the frequency of each symptom on the same scale. If a participant had not given any answer to any of the symptoms, we considered they had not answered this section and excluded them from the analysis. On the other hand, those who had ticked at least one symptom were included in the analysis and were considered not to have the symptoms they had not ticked. Since the back and the joints cover the most common sites of musculoskeletal pain among older adults, we used the term intermittent or daily musculoskeletal pain to refer to the back and/or joint pain the participants reported having sometimes or daily, respectively.

\subsubsection{Analgesics Use}

The participants were asked to list their regular prescription medications in the questionnaire. The prescribed analgesics 
were classified according to the WHO Anatomical Therapeutic Chemical classification system. Classes M01AB (diclofenac), M01AE (ibuprofen, ketoprofen, naproxen), M01AC01 (piroxicam), and M01AX (nabumetone) were referred to as non-selective NSAIDs, class M01AH coxibs (celecoxib, etoricoxib) and M01AC06 (meloxicam) were referred to as selective COX2 inhibitors, class M02AA (topical piroxicam, diclofenac, ibuprofen, ketoprofen) were referred to as topical NSAIDs, while class N01A opioids were subdivided into weak (buprenorphine, codeine, dextropropoxyphene, and tramadol) and strong opioids (methadone hydrochloride, morphine, fentanyl, and oxycodone). A combination analgesic frequently used in Finland containing codeine and paracetamol was classified as a weak opioid. Paracetamol (class N02B, other analgesics and antipyretics) was handled as a separate class. We excluded the following medicines that are potentially used for pain management from the analysis due to their various non-analgesic indications: antiepileptics (e.g., gabapentin, pregabalin) and antidepressants (e.g., duloxetine). Low-dose acetylsalicylic acid was not considered an analgesic in the study. We did not differentiate between those who took one analgesic daily from those taking several regular analgesics.

Only regular prescription analgesics were reported in the questionnaire and analyzed in this study. Over-the-counter analgesic use was not addressed.

\subsection{Statistical Analysis}

The characteristics are presented as means with standard deviation (SD) for continuous variables and as frequencies with percentages for categorical variables. Linearity across the three cohorts was evaluated using the Cochran-Armitage test (Chi-square test for trend), logistic models, and analysis of variance with an appropriate contrast (orthogonal). When adjusting for confounding factors, a logistic regression model was applied; models included age, sex, and Charlson comorbidity index as covariates. In case of violation of the assumptions (e.g., non-normality) for continuous variables, a bootstrap-type method or Monte Carlo $p$ values (small number of observations) for categorical variables were used. The normality of variables was evaluated graphically and by using the Shapiro-Wilk $W$ test. Stata 16.1, StataCorp LP (College Station, TX, USA) statistical package was used for statistical analyses.

\section{Results}

Table 1 presents the cohort characteristics in 1999, 2009, and 2019. The number of participants eligible for analysis was 2473,1583 , and 1651 in 1999, 2009, and 2019, respectively (total $n=5707$ ). The percentage of women was highest in the first cohort in 1999 (71\%) and decreased to $69 \%$ in 2009 and $64 \%$ in 2019 . The proportion of oldest-old participants (aged 90-95 years) was higher in 2009 and 2019 than in 1999. The proportion of participants who received over 8 years of schooling increased with every study wave from 1999 to 2019. The proportion of widowed participants decreased from 1999 to 2019 . The Charlson comorbidity index decreased from 2.1 to 1.7 , while the number of prescription medicines increased on average from 3.3 to 4.9.

Two in three reported being able to move outside unaided and the cohorts did not differ from each other in this respect. Most participants rated their health as good in all study waves; the highest percentage was $82 \%$ in 2019 .

The overall percentage of people reporting musculoskeletal pain was $57 \%$ in $1999,60 \%$ in 2009, and $61 \%$ in 2019 . Approximately one quarter of participants reported daily pain that hinders activity (24\% in $1999,27 \%$ in 2009 , and $24 \%$ in 2019), while approximately one third of participants reported intermittent pain that hinders activity (33\% in 1999, $33 \%$ in 2009 , and $37 \%$ in 2019). The prevalence of daily pain did not change from 1999 to 2019 ( $p=0.67)$. Joint pain was more frequent than back pain and its prevalence increased from 1999 to 2019 (Table 1).

The regular use of prescription analgesics increased from 1999 (9\%) to 2019 (16\%) (Table 1). Of the various analgesic classes, the largest increase was seen in regular paracetamol use, from $2 \%$ in 1999 to $11 \%$ in 2019 . The use of nonselective NSAIDs decreased from 5\% in 1999 to $2 \%$ in 2019, and the use of selective COX-2 inhibitors increased (but remained low) from $0 \%(n=3)$ in 1999 to $1 \%(n=16)$ in 2019. Very few participants regularly used prescribed topical NSAIDs. Although the regular use of prescription opioids increased from 1999 to 2019, it remained low (2-4\%).

From 1999 to 2019, the regular use of one or more analgesics increased from 14 to $21 \%$ among those reporting musculoskeletal pain and from 3 to $7 \%$ among those not reporting pain. Figure 1 shows the adjusted prevalence of regular analgesic use among people reporting intermittent or daily musculoskeletal pain and among those not reporting pain. Regular analgesic use increased in both groups from 1999 to 2019 ( $p<0.001$ for cohort, $p<0.001$ for pain group, $p<0.25$ for interaction, adjusted for age, sex, and Charlson comorbidity index).

Among those reporting daily pain, the prevalence of analgesic use increased from $20 \%$ in 1999 to $32 \%$ in 2019 . Among those reporting intermittent pain, regular analgesic use increased from $9 \%$ in 1999 to $14 \%$ in 2019. Figure 2 shows the adjusted prevalence of regular analgesic use among people reporting intermittent or daily musculoskeletal pain, respectively. Both groups show an increasing trend between 1999 and $2019(p<0.001$ for cohort, $p<0.001$ for pain group, $p=0.89$ for interaction, adjusted for age, sex, and Charlson comorbidity index). 
Table 1 Cohort characteristics, prevalence of pain, and prescribed analgesics in 1999, 2009, and 2019

\begin{tabular}{|c|c|c|c|c|}
\hline & $\begin{array}{l}1999 \\
n=2473\end{array}$ & $\begin{array}{l}2009 \\
n=1583\end{array}$ & $\begin{array}{l}2019 \\
n=1651\end{array}$ & $p$ value* \\
\hline Women, $n(\%)$ & $1762(71)$ & $1089(69)$ & $1064(64)$ & $<0.001$ \\
\hline Age, $n(\%)$ & & & & $<0.001$ \\
\hline 75 years & $701(28)$ & $386(24)$ & $405(25)$ & \\
\hline 80 years & $674(27)$ & $378(24)$ & $399(24)$ & \\
\hline 85 years & $617(25)$ & $349(22)$ & $367(22)$ & \\
\hline 90-95 years & $481(19)$ & $470(30)$ & $480(29)$ & \\
\hline Education $<8$ years, $n(\%)$ & $1267(53)$ & $578(37)$ & $396(24)$ & $<0.001$ \\
\hline Widowed, $n(\%)$ & $1125(47)$ & $658(42)$ & $586(36)$ & $<0.001$ \\
\hline Charlson comorbidity index ${ }^{\mathrm{a}}$, mean (SD) & $2.1(2.0)$ & $2.0(1.8)$ & $1.7(1.6)$ & $<0.001$ \\
\hline Number of prescribed drugs, mean (SD) & $3.3(2.9)$ & $4.8(3.6)$ & $4.9(3.7)$ & $<0.001$ \\
\hline Moves outside unaided, $n(\%)$ & $1582(64)$ & $907(57)$ & $1052(64)$ & 0.52 \\
\hline Good self-rated health, $n(\%)$ & $1819(77)$ & $1150(74)$ & $1328(82)$ & $<0.001$ \\
\hline $\begin{array}{l}\text { Intermittent or daily joint or back pain within } 2 \\
\text { weeks, } n(\%)\end{array}$ & $1406(57)$ & $947(60)$ & $1006(61)$ & $0.007[<0.001]$ \\
\hline Back pain & $979(40)$ & $660(42)$ & $698(42)$ & \\
\hline Joint pain & $1071(43)$ & $749(47)$ & $799(48)$ & \\
\hline Daily prescribed analgesic, $n(\%)$ & $224(9)$ & $263(17)$ & $256(16)$ & $<0.001[<0.001]$ \\
\hline Non-selective NSAID & $129(5)$ & $58(4)$ & $39(2)$ & $<0.001[0.002]$ \\
\hline Selective COX-2 inhibitor & $3(0)$ & $20(1)$ & $16(1)$ & $0.001[0.003]$ \\
\hline Paracetamol & $60(2)$ & $168(11)$ & $181(11)$ & $<0.001[<0.001]$ \\
\hline Opioid & $55(2)$ & $67(4)$ & $57(3)$ & $0.012[0.002]$ \\
\hline Weak opioid & $51(2)$ & $58(4)$ & $46(3)$ & \\
\hline Strong opioid & $5(0)$ & $9(1)$ & $12(1)$ & \\
\hline
\end{tabular}

NSAID = non-steroidal anti-inflammatory drug, SD = standard deviation of the mean

* $p$ for linearity. $p$ values in square brackets are from analyses adjusted for age, sex, and the Charlson comorbidity index

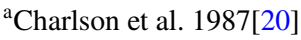

\section{Discussion}

Our study revealed that the prevalence of regular analgesic treatment has increased among community-dwelling older persons aged 75-95 years from 1999 to 2019. The use of paracetamol has significantly increased and is now the most commonly used analgesic. The use of opioids has remained modest. On the other hand, more than half of the participants reported musculoskeletal pain in 2019, and this proportion did not decrease since 1999. Only one third of those with daily pain were taking a regular analgesic prescribed by their doctor, suggesting continuous undertreatment of pain (at least with prescription drugs) in older persons.

Our findings concerning the prevalence of pain are consistent with previous research, which reported the prevalence of pain to be approximately $52-64 \%$ in the older population $[2-4,8]$. However, these studies are not directly comparable since the definition of pain and its persistence varied between studies. To our knowledge, there are no previous studies reporting time trends in musculoskeletal pain in older community-dwelling populations except our prior report [9]. Our study suggests that the prevalence of pain has not decreased even after adjustment for age, sex, and comorbidities. Thus, the increasing proportion of the oldest age groups does not explain the high prevalence of pain in the most recent cohorts. Furthermore, even though fewer were widowed and more participants were better educated, pain remained at least as prevalent in later cohorts as in the first one. Consistent with previous studies, pain in the older population may remain undertreated [11].

In our most recent cohort from 2019, $16 \%$ of participants were taking regular analgesic medication prescribed by their doctor. This value is consistent with the 2002 AGS panel on persistent pain in older persons [10], in which $18 \%$ of the geriatric population was reported to take analgesics at least several times per week. The analgesic profile in our study consistent with recommendations on analgesic use in the older population [21, 22] and has improved from 1999 to 2019; the use of paracetamol has increased while the regular use of non-selective NSAIDs has decreased. The avoidance of NSAIDs may be due in part to the increased use of anticoagulant therapy [23]. The popularity of paracetamol 


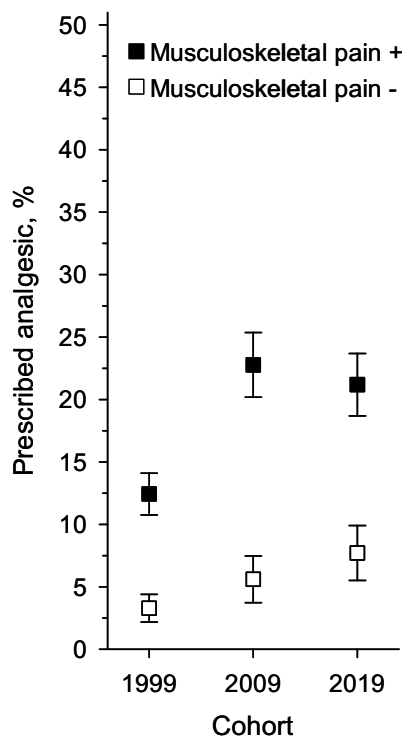

Fig. 1 Adjusted prevalence of the regular use of prescribed analgesics among participants reporting musculoskeletal pain (in black) and among participants not reporting musculoskeletal pain (in white) in 1999, 2009, and 2019. Percentages were adjusted for age, sex, and Charlson comorbidity index with $95 \%$ confidence intervals ( $p<0.001$ for cohort, $p<0.001$ for pain group, $p=0.25$ for interaction). $n=2473, n=1583$, and $n=1651$ in 1999, 2009, and 2019, respectively

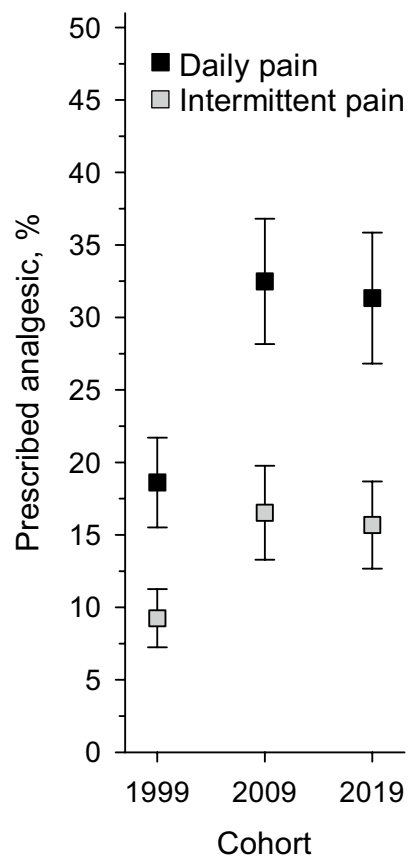

Fig. 2 Adjusted prevalence of the regular use of prescribed analgesics among participants reporting intermittent (in grey) or daily musculoskeletal pain (in black) in 1999, 2009, and 2019. Percentages were adjusted for age, sex, and Charlson comorbidity index with 95\% confidence intervals $(p<0.001$ for cohort, $p<0.001$ for pain group, $p=0.89$ for interaction). $n=2473, n=1583$, and $n=1651$ in 1999, 2009 , and 2019, respectively over other analgesics among older adults is consistent with a prior study [24].

The use of prescribed analgesics increased markedly from 1999 to 2009 in our cohorts among those experiencing both daily as well as intermittent musculoskeletal pain. This is mainly due to the increased use of paracetamol. More than one in ten of those who reported intermittent musculoskeletal pain reported regular analgesic use in 2019. It may be questioned whether such analgesic use is appropriate. Some of these participants might have suffered from daily pain had they not taken a regular analgesic; also, they may have other painful conditions that our study fails to cover.

Stewart et al. [25] have recently examined analgesic use among community-dwelling older persons. In their study, $28 \%$ of those with pain that lasted over 2 weeks were taking a regular analgesic. Here, we report a slightly higher percentage (32\% in 2019) of regular analgesic use among people experiencing daily pain. Interestingly, $31 \%$ of those studied by Stewart et al. were using non-pharmacological strategies alone to manage their pain. The guidelines for treating pain in the older population emphasize that pharmacological and non-pharmacological approaches (e.g., physical therapy, exercise, acupuncture) should be combined to achieve optimal effect $[22,26]$. In fact, the underuse of non-pharmacological approaches may be one important reason why so many older people still suffer from daily pain. Overall, pharmacological pain management in older adults is complicated by the limited selection of safe first-line analgesics; paracetamol is the only medicine considered generally safe for older persons. The use of all other analgesics (which are often more efficacious than paracetamol) is limited by the risk of serious adverse effects.

The studies reporting regular prescribed and pro re nata (as needed) analgesics [19] and even over-the-counter analgesics [24] have shown a higher prevalence of analgesic use than that observed in our study. In fact, the short-term use of analgesics may be much more widespread than the regular use we investigated. However, there is evidence that a significant proportion of older adults use prescription analgesics less than what is prescribed and only when the pain is severe [27]. Having mastery over medication use may be an important factor in maintaining a sense of self-efficacy [28].

Importantly, we did not observe an epidemic of regular opioid use among community-dwelling older persons; only $3 \%$ of our 2019 cohort was taking opioids regularly and the increase from 1999 was modest. This percentage is less than half of what Haasum et al. [18] and Steinman et al. [12] reported in Sweden and in the USA. However, both of these studies included as-needed opioid use. Among patients with back pain, Enthoven et al. [24] found that almost $20 \%$ of older patients had taken opioids at baseline, while TaylorStokes et al. [29] observed that $32-79 \%$ of patients had received opioids from their doctor in the USA. Knowing that 
the prevalence of opioid use has been increasing in Finnish long-term care settings [30], it is reassuring to observe that opioids are not regularly used by a larger proportion of community-dwelling older persons in our study population.

This study had several strengths. First, we studied and compared relatively large cross-sectional community-dwelling cohorts that were retrieved from an equivalent population at three time points, thus enabling time-trend analysis. Second, the questions were the same and the response rate remained good in all study waves. Third, the recall time of 2 weeks is likely to be reliable when assessing pain [3]. Fourth, self-reported use of analgesics may provide more reliable information on regular drug use than from pharmacy records only.

This study had some weaknesses. First, we did not examine pain intensity. Also, the 2-week period can be considered short to examine pain. However, it gives a good estimate of pain prevalence at a population level. Second, use of overthe-counter medicines or pro re nata drugs was not examined, which might underestimate analgesic use. Third, we did not address non-pharmacological treatments that are considered essential for pain management in the older population. Lastly, our cohort data were cross-sectional; thus, we could not assess causality or temporal interdependence between pain and analgesic medication. Our cohort data consists of community-dwelling older adults in the urban Helsinki area. Therefore, the results may not directly apply to other cultural contexts or more rural populations even in Finland.

\section{Conclusions}

The prevalence of musculoskeletal pain was high in all study waves and did not decrease with increasing analgesic use. Although the use of regular prescribed analgesics increased from 1999 to 2019, pain remains undertreated in the community-dwelling older population aged $>75$ years. Over 20 years, the use of paracetamol increased while the use of non-selective NSAIDs decreased. We did not observe a major increase in regular opioid use among communitydwelling older persons from 1999 to 2019. More studies are needed to explore the intensity of pain and the efficacy of both pharmacological and non-pharmacological approaches in pain management among older adults.

\section{Declarations}

Funding Open access funding provided by University of Helsinki including Helsinki University Central Hospital. This study was funded by the Päivikki and Sakari Sohlberg Foundation, the Kunnanlääkäri Uulo Arhio Foundation, and Helsinki University Hospital VTR funding. The funders had no role in study design, data collection and analysis, decision to publish, or preparation of the manuscript.
Conflict of interest Dr Strandberg reports educational cooperation with Servier, Orion, and Novartis, and is a member of the European Geriatric Medicine Society (EuGMS) special interest group on cardiovascular medicine in older people and diabetes in older people. Dr Pitkälä, Dr Öhman, Dr Karppinen, Dr Tilvis, Lehti, Knuutila, Rinkinen, Dr Roitto, Dr Aalto, and Kautiainen declare no conflicts of interest.

Availability of data and material The datasets generated during and analyzed during the current study are available from the corresponding author on reasonable request.

Code availability Not applicable.

Authors' contributions Prof. Pitkälä had full access to all data in the study and takes responsibility for the integrity of the data and the accuracy of the analyses. Prof. Pitkälä is the guarantor. Study concept and design: Lehti, Aalto, Roitto, Öhman, Rinkinen, Knuutila, Kautiainen, Karppinen, Tilvis, Strandberg, Pitkälä. Acquisition of data: Lehti, Rinkinen, Kautiainen, Pitkälä. Analysis and interpretation of data: Lehti, Kautiainen, Pitkälä. Drafting of the manuscript: Lehti. Critical revision of the manuscript for important intellectual content: Lehti, Rinkinen, Aalto, Roitto, Öhman, Knuutila, Kautiainen, Karppinen, Tilvis, Strandberg, Pitkälä. Statistical analysis: Lehti, Kautiainen, Pitkälä. Obtained funding: Pitkälä, Lehti.

Ethics approval The study design was approved by the Helsinki University Hospital Ethics Committee.

Consent to participate Not applicable. Data was collected as a survey and was analyzed anonymously. Cover letter for the survey included a statement of confidentiality.

Consent for publication All authors gave explicit consent to submit and publish the article.

Open Access This article is licensed under a Creative Commons Attribution-NonCommercial 4.0 International License, which permits any non-commercial use, sharing, adaptation, distribution and reproduction in any medium or format, as long as you give appropriate credit to the original author(s) and the source, provide a link to the Creative Commons licence, and indicate if changes were made. The images or other third party material in this article are included in the article's Creative Commons licence, unless indicated otherwise in a credit line to the material. If material is not included in the article's Creative Commons licence and your intended use is not permitted by statutory regulation or exceeds the permitted use, you will need to obtain permission directly from the copyright holder. To view a copy of this licence, visit http://creativecommons.org/licenses/by-nc/4.0/.

\section{References}

1. Mäntyselkä P, Kumpusalo E, Ahonen R, Kumpusalo A, Kauhanen $\mathrm{J}$, Viinamäki H, Halonen P, Takala J. Pain as a reason to visit the doctor: a study in Finnish primary health care. Pain. 2001. https:// doi.org/10.1016/s0304-3959(00)00361-4.

2. Ray L, Lipton RB, Zimmerman ME, Katz MJ, Derby CA. Mechanisms of association between obesity and chronic pain in the elderly. Pain. 2011. https://doi.org/10.1016/j.pain.2010.08.043.

3. Patel KV, Guralnik JM, Dansie EJ, Turk DC. Prevalence and impact of pain among older adults in the United States: findings from the 2011 National Health and Aging Trends Study. Pain. 2013. https://doi.org/10.1016/j.pain.2013.07.029. 
4. Brochet B, Michel P, Barberger-Gateau P, Dartigues J-F. Population-based study of pain in elderly people: a descriptive survey. Age Ageing. 1998. https://doi.org/10.1093/ageing/27.3.279.

5. Abdulla A, Adams N, Bone M, Elliott AM, Gaffin J, Jones D, Knaggs R, Martin D, Sampson L, Schofield P, British Geriatric Society. Guidance on the management of pain in older people. Age Ageing. 2013. https://doi.org/10.1093/ageing/afs200.

6. Rapo-Pylkkö S, Haanpää M, Liira H. Chronic pain among community-dwelling elderly: a population-based clinical study. Scand J Prim Health Care. 2016. https://doi.org/10.3109/02813432.2016. 1160628.

7. Pitkala KH, Strandberg TE, Tilvis RS. Management of nonmalignant pain in home-dwelling older people: a population-based survey. J Am Geriatr Soc. 2002. https://doi.org/10.1046/j.15325415.2002.50517.x.

8. Watkins EA, Wollan PC, Melton LJ 3rd, Yawn BP. A population in pain: report from the Olmsted County health study. Pain Med. 2008. https://doi.org/10.1111/j.1526-4637.2007.00280.x.

9. Halla-aho SM, Tilvis RS, Strandberg TE, Pitkälä KH. Musculoskeletal pain and its treatment among older home-dwelling people: 10-year changes in two Finnish birth cohorts. Arch Gerontol Geriatr. 2013. https://doi.org/10.1016/j.archger.2012.08.014.

10. AGS Panel on Persistent Pain in Older Persons. The management of persistent pain in older persons. J Am Geriatr Soc. 2002. https://doi.org/10.1046/j.1532-5415.50.6s.1.x.

11. Nawai A, Leveille SG, Shmerling RH, van der Leeuw G, Bean JF. Pain severity and pharmacologic pain management among community-living older adults: the MOBILIZE Boston study. Aging Clin Exp Res. 2017. https://doi.org/10.1007/s40520-016-0700-9.

12. Steinman MA, Komaiko KD, Fung KZ, Ritchie CS. Use of opioids and other analgesics by older adults in the United States, 1999-2010. Pain Med. 2015. https://doi.org/10.1111/pme.12613.

13. Pitkala KH, Juola AL, Hosia H, Teramura-Gronblad M, Soini H, Savikko N, Bell JS. Eight-year trends in the use of opioids, other analgesics, and psychotropic medications among institutionalized older people in Finland. J Am Med Dir Assoc. 2015. https://doi. org/10.1016/j.jamda.2015.06.009.

14. Zerzan JT, Morden NE, Soumerai S, Ross-Degnan D, Roughead E, Zhang F, Simoni-Wastila L, Sullivan SD. Trends and geographic variation of opiate medication use in state Medicaid feefor-service programs, 1996 to 2002. Med Care. 2006. https://doi. org/10.1097/01.mlr.0000228025.04535.25.

15. Hamunen K, Paakkari P, Kalso E. Trends in opioid consumption in the Nordic countries 2002-2006. Eur J Pain. 2009. https://doi. org/10.1016/j.ejpain.2008.11.006.

16. Sites BD, Beach ML, Davis MA. Increases in the use of prescription opioid analgesics and the lack of improvement in disability metrics among users. Reg Anesth Pain Med. 2014. https://doi.org/ 10.1097/AAP.0000000000000022.

17. Oktora MP, Alfian SD, Bos HJ, Schuiling-Veninga CCM, Taxis K, Hak E, Denig P. Trends in polypharmacy and potentially inappropriate medication (PIM) in older and middle-aged people treated for diabetes. Br J Clin Pharmacol. 2020. https://doi.org/10.1111/ bcp. 14685 .

18. Haasum Y, Fastbom J, Fratiglioni L, Kåreholt I, Johnell K. Pain treatment in elderly persons with and without dementia: a population-based study of institutionalized and home-dwelling elderly. Drugs Aging. 2011. https://doi.org/10.2165/11587040-00000 0000-00000

19. Marttinen MK, Kautiainen H, Haanpää M, Pohjankoski H, Hintikka J, Kauppi MJ. Analgesic purchases among older adults-a population-based study. BMC Public Health. 2021. https://doi. org/10.1186/s12889-021-10272-3.

20. Charlson ME, Pompei P, Ales KL, MacKenzie CR. A new method of classifying prognostic comorbidity in longitudinal studies (development and validation). J Chronic Dis. 1987;40:373-83.

21. By the 2019 American Geriatrics Society Beers Criteria ${ }^{\circledR}$ Update Expert Panel. American Geriatrics Society. Updated AGS Beers Criteria ${ }^{\circledR}$ for potentially inappropriate medication use in older adults. J Am Geriatr Soc. 2019. https://doi.org/10.1111/jgs.15767.

22. Makris UE, Abrams RC, Gurland B, Reid MC. Management of persistent pain in the older patient: a clinical review. JAMA. 2014. https://doi.org/10.1001/jama.2014.9405.

23. Official Statistics of Finland: Finnish Statistics on Medicines 2019 [web publication]. ISSN 2490-0109. Helsinki: Kela. http://urn.fi/ URN:NBN:fi-fe20201217101079. Accessed 17 Mar 2021.

24. Enthoven WT, Scheele J, Bierma-Zeinstra SM, Bueving HJ, Bohnen AM, Peul WC, van Tulder MW, Berger MY, Koes BW, Luijsterburg PA. Analgesic use in older adults with back pain: the BACE study. Pain Med. 2014. https://doi.org/10.1111/pme.12515.

25. Stewart C, Leveille SG, Shmerling RH, Samelson EJ, Bean JF, Schofield P. Management of persistent pain in older adults: the MOBILIZE Boston Study. J Am Geriatr Soc. 2012. https://doi. org/10.1111/j.1532-5415.2012.04197.x.

26. Bicket MC, Mao J. Chronic pain in older adults. Anesthesiol Clin. 2015. https://doi.org/10.1016/j.anclin.2015.05.011.

27. Reid MC, Henderson CR Jr, Papaleontiou M, Amanfo L, Olkhovskaya Y, Moore AA, Parikh SS, Turner BJ. Characteristics of older adults receiving opioids in primary care: treatment duration and outcomes. Pain Med. 2010. https://doi.org/10.1111/j.1526-4637. 2010.00883.x.

28. Gecas V. The social psychology of self-efficacy. Annu Rev Sociol. 1989. https://doi.org/10.1146/annurev.so.15.080189.001451.

29. Taylor-Stokes G, Lobosco S, Pike J, Sadosky AB, Ross E. Relationship between patient-reported chronic low back pain severity and medication resources. Clin Ther. 2011. https://doi.org/10. 1016/j.clinthera.2011.09.026.

30. Roitto HM, Kautiainen H, Aalto UL, Öhman H, Laurila J, Pitkälä KH. Fourteen-year trends in the use of psychotropic medications, opioids, and other sedatives among Institutionalized Older People in Helsinki, Finland. J Am Med Dir Assoc. 2019. https://doi.org/ 10.1016/j.jamda.2018.12.022. 